Zhang, W., \& Duan, C. (2017). Construction and Implementation of Institutional E-learning Development Framework in Continuing Higher Education. Journal of Educational Technology Development and Exchange, 10(1), 11-25.

\title{
Construction and Implementation of Institutional E-learning Development Framework in Continuing Higher Education
}

\author{
Weiyuan Zhang \\ Beijing Normal University \\ Chenggui Duan
}

Chu Hai College of Higher Education, Hong Kong

\begin{abstract}
E-learning has become a popular teaching and learning mode in the education and training sectors in the digital age. Many studies have been done in the field of e-learning at course level. However, limited literature has been found about e-learning strategic development in continuing higher education sector at the institutional level. The purpose of this study was to explore the institutional development and implementation of e-learning, using the School of Professional and Continuing Education at the University of Hong Kong (HKU SPACE) as a case. In this paper, the comprehensive e-learning development framework at institutional level is proposed and seven dimensions under the framework are explored, including e-learning policy, e-learning organizational structure, e-learning systems, m-learning APP, e-learning courses, e-learning training and support, and e-learning evaluation. Based on the results of the case study, it is suggested that policy and organizational structure are essential to ensure the implementation of e-learning in self-financed continuing higher education institutions. The e-learning systems, m-learning applications, e-courses, training and support, and e-learning evaluation should be considered and integrated as a whole in order to maintain continuous development and enhancement in e-learning.It is hoped that the institutional e-learning development framework presented in this paper can provide a benchmark for continuing higher education institutions to make e-learning strategic planning.
\end{abstract}

Keywords: continuing higher education; institutional research; e-learning; m-learning; strategic planning

\section{Introduction}

The use of information and communication technology (ICT) brings great opportunities and challenges for new development and innovations in all areas, worldwide. With the advantages of flexibility, richness, resource-sharing and cost-effectiveness, e-learning has become an increasingly important learning and teaching mode in the education and training sectors (Zhang, 2013). 
E-learning development can be at course and institutional levels. Many studies have been done on its use at course level in continuing higher education (Zhang and Cheng, 2012; Pawlyn, 2012; Hall, 2013; Giesbers, Rienties, Tempelaar\& Gijselaers, 2013; Akyol \& Garrison, 2014; Singh \& Bajaj, 2015; Wanner, \& Palmer, 2015; Scanlon, McAndrew\& O'Shea, 2015). Some literature has been devoted to different aspects of e-learning development from the view of institutions. Czerniewicz and Brown (2009) found that there was a clear relationship between institutional policy, organisational culture and e-learning use after an investigation of four diverse South African universities. McGill, Klobas and Renzi (2014) reported that characteristics of the technology and institutional support were dominant factors affecting the continuation or discontinuation of e-learning initiatives in universities after their analysis of 64 e-learning projects. Guan, Ding and Ho (2015) pointed out that technical training or preparations are needed prior to e-learning and that infrastructure needs to be improved, in order to promote online learning for adult learners. Gunn (2010) investigated a number of successful innovations and identified several influences on the sustainability of these initiatives: supportive organisational structures, a vision shared by all,and staff accountability. O'Dowd (2013) surveyed over 300 university lecturers and students and found that successful e-learning implementation required advocacy among administrators, faculty, and other institutional personnel.Taylor and Newton (2013) stated that a shared vision and energy that touches all parts of an organisation are necessary for systematic implementation of e-learning.

The success of institutional e-learning development depends on many factors, including policy, management, technology and pedagogy,with joint efforts by management personnel, programme leaders, teachers, instructional designers, technicians, multimedia developers, and e-learning trainers. However, little information is available on comprehensive e-learning strategic development in self-financed continuing higher education at the institutional level.

The purpose of this paper is to describe and analyse strategic development and the implementation of e-learning in the continuing education sector at institutional level, using the School of Professional and Continuing Education at the University of Hong Kong (HKU SPACE) as a case study. It is expected that the experience of the institutional e-learning development at HKU SPACE can be shared by colleagues and contribute to the literature in this area.

\section{Construction of Institutional E-learning Development Framework at HKU SPACE}

HKU SPACE is one of Hong Kong's leading continuing higher education providers. The annual course enrolments at HKU SPACE are close to 80,790 , with over 1,000 fulltime staff members, and some 2,100 parttime teachers. Course enrolments since 1956 have exceeded 2.55 million (HKU SPACE, 2015). As most of teachers are part-time, the establishment of institutional strategies is essential for sustainable and healthy development in e-learning.

Graham et. al. proposed three aspects of institutional blended e-learning development, strategy, structure and support (Graham, Woodfield\&Harrison, 2013). In order to develop an effective institutional e-learning development framework, the HKU SPACE Centre for Cyber Learning conducted three internal surveys of users' experiences of pilot e-learning courses and needs analyses in e-learning and m-learning (HKU SPACE, 
2011; HKU SPACE, 2012; HKU SPACE, 2013a).

Based on the literature review and results of an internal survey about the need for e-learning and m-learning conducted with management personnel, programme leaders, teachers and students, the e-learning development framework at HKU SPACE was established at the School level, as summarized in Figure 1.

Figure 1 displays the institutional e-learning development framework with the following seven dimensions at HKU SPACE: (1) e-learning policy, i.e. HKU SPACE's e-learning policy; (2) e-learning organizational structure, including a steering committee for e-learning and m-learning development, a task-force for e-learning and m-learning, and the Centre for Cyber Learning; (3) e-learning systems,including e-learning knowledge management system and e-learning management system; (4) m-learning APP, i.e. HKU SPACE M-learning SOUL 2.0 APP; (5) e-learning courses, including needs analyses, e-learning instructional design, and multimedia design and development; (6) e-learning

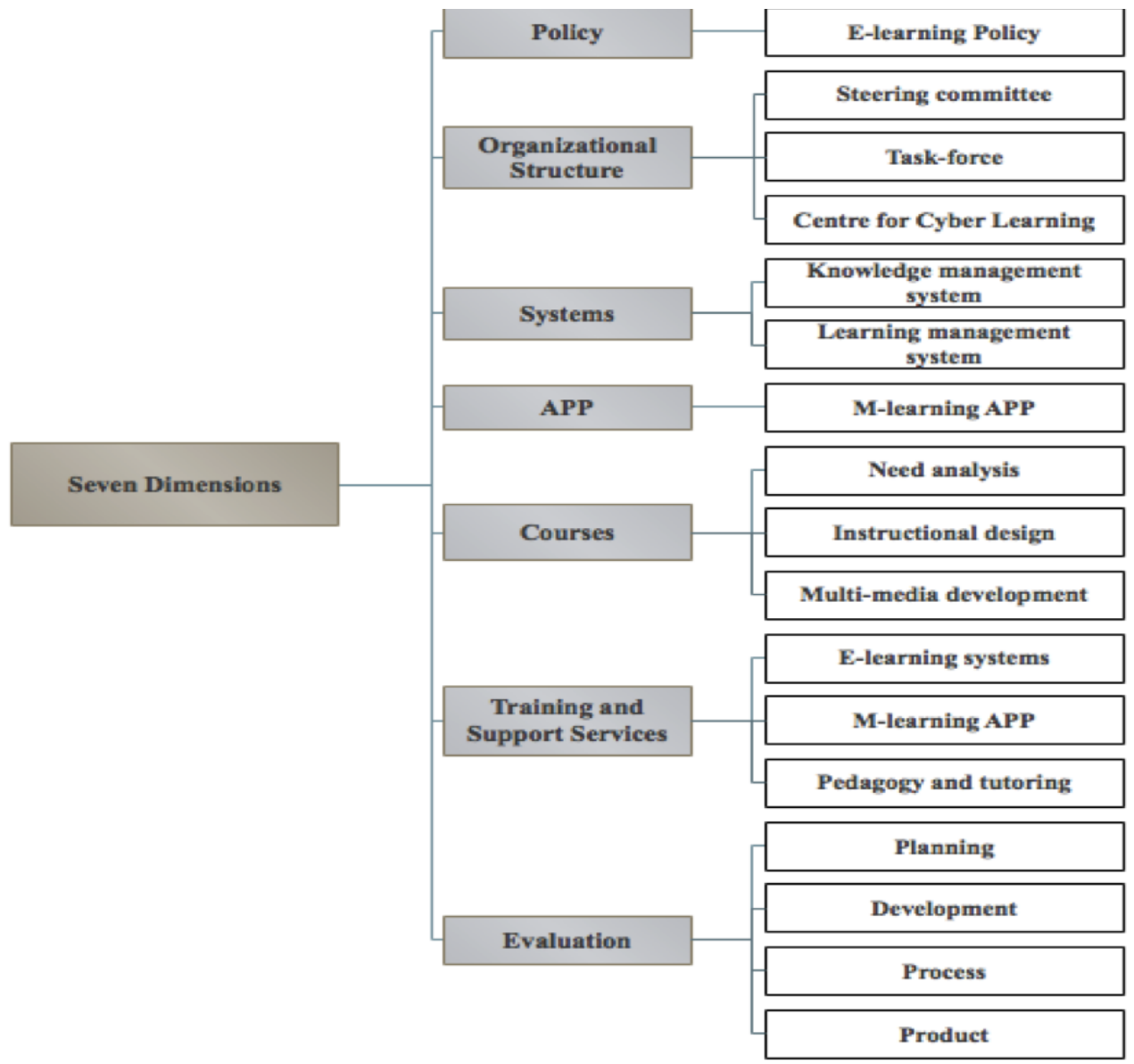

Figure 1. Institutional e-learning development framework at HKU SPACE 
training and support services, including the use of e-learning systems and m-learning APP, and e-learning pedagogy and tutoring; (7) e-learning evaluations, including planning evaluation, development evaluation, process evaluation and product evaluation. The following section will describe and analyse the implementation of this e-learning development framework.

\section{Implementation of Institutional E-learning Framework at HKU SPACE}

As mentioned in the previous section, the seven dimensions of e-learning, namely e-learning policy, e-learning organizational structure, e-learning systems, m-learning APP, e-learning courses, e-learning training and support, and e-learning evaluation, form a comprehensive e-learning development framework at an institutional level at HKU SPACE.

\section{E-learning Policy}

HKU SPACE strives to enhance access to education for career advancement and personal development, and believes that the appropriate use of e-learning has the potential to improve learning opportunities for learners, and the quality of instruction. To ensure the effective implementation of e-learning, an internal e-learning policy was introduced,which addresses the benefits to teachers and learners. This policy defines the roles of programme teams and teachers, as well as serving as a guideline for programmes to use e-learning environments in their teaching and learning.

The policy statement expresses the notion of a minimum provision of e-learning and define show this minimum provision is to be provided through the School's own e-learning platform. The programme teams and teachers are requested to use e-learning components to enhance teaching and learning effectiveness; they are encouraged to use blended learning/ integrated learning mode to reduce teaching hours and even to develop pure online courses. Regarding implementation, the policy outlines the respective roles of programme directors, instructors and the Centre for Cyber Learningin working together to ensure that the potential benefits of e-learning to all the learners can be realized. If additional resources are required to support the development, Programme Teams, under the support of Centre for Cyber Learning, can apply to a School's funds for e-learning development (HKU SPACE, 2013b).

\section{E-learning Organizational Structure}

The e-learning development is governed by the Steering Committee for E-learning and M-learning Development, which consists of internal senior management personnel and external e-learning experts who provide advice and guidance on strategic planning,the work and foci of the Centre of Cyber Learning,and internal and external projects in order to ensure coherent efforts in continuous and healthy e-learning and m-learning development through communication and consensus building among the various units involved.

Under the Steering Committee for E-learning and M-learning Development, the Task Forcefor the Promotion of e-Learning and $\mathrm{m}$-Learning is responsible for the promotion of e-learning and m-learning at HKU SPACE. The members of the Task Force include representatives from all teaching colleges and units. The major duties are to plan, implement and coordinate the promotion of e-learning and m-learning, and recommend support to new initiatives with respect to the promotion of e-learning and m-learning.

For operation governance, the Centre 
for Cyber Learning consists of four teams specializing in different functions, including e-learning and $\mathrm{m}$-learning system and platform design and development, e-learning course design and development, e-learning training and user support services, and e-learning and m-learning research and development. The Centre provides all services relating to the use of e-learning systems, m-learning APPs, instructional design, pedagogy and tutoring, multi-media courseware development, training and individual support to all staff, teachers and students.

\section{E-learning Knowledge Management System}

The knowledge management platform, the "SPACE Knowledge and Information Exchange System" (SKIES), was designed and developed by the Centre for Cyber Learning and is used to accommodate all existing teaching and learning resources. The SKIES is an institutional repository for teaching and learning materials, which supports various teaching and learning materials such as documents, images, interactive flash files, web pages, video, audio, self-contained learning packages, quizzes and exercises. The platform provides an open and collaborative environment aimed at promoting and enhancing teaching effectiveness. With SKIES, the e-learning resources can be shared, re-used, adapted or adopted, or rebuilt by teachers at any time, and anywhere. The knowledge-building environment consists of four components: (a) storage, (b) access, (c) distribution, and (d) encouragement of collaboration.

Using SKIES (Figure 2), teachers are able to locate materials in the platform. The uploaded materials are categorized into relevant areas. A basic search action enables data to be located through the use of titles or description phrases. The development team has categorized and uploaded materials based on their formats or nature, e.g. video, audio, photos and documents. Indeed, these classifications both help the person who uploads a piece of material and offer the searcher a quicker way to view, access and

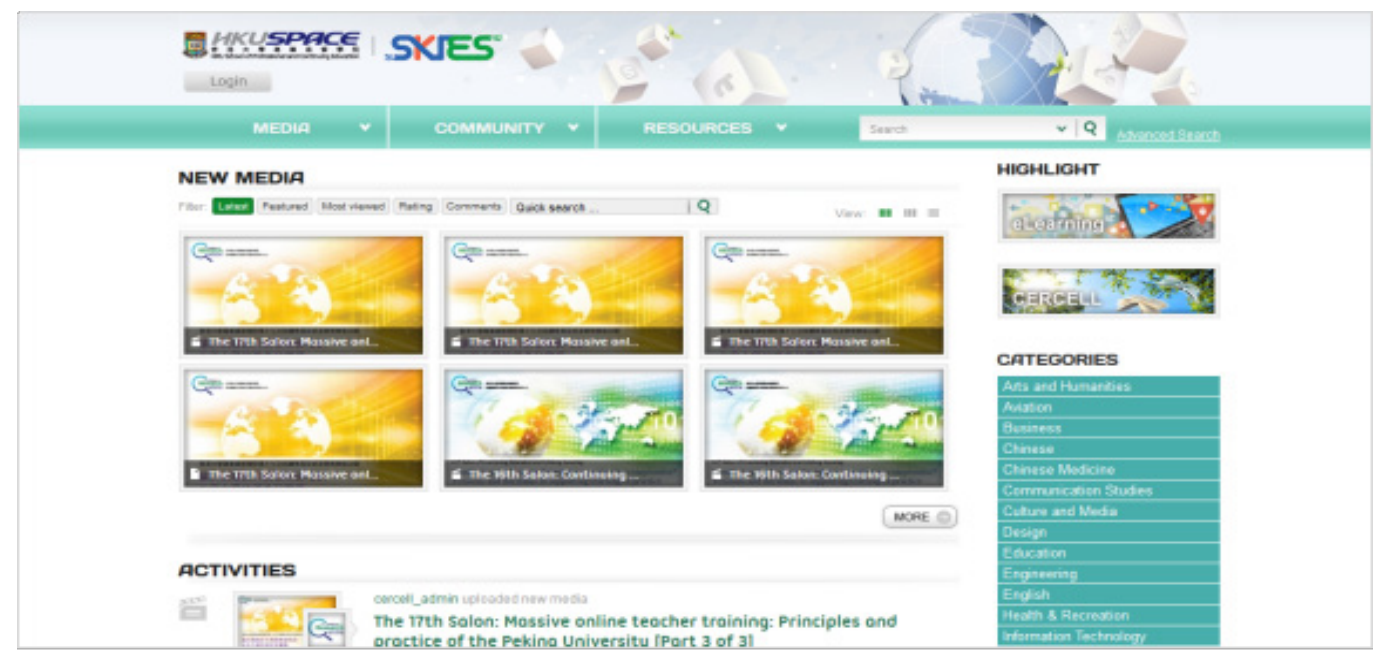

Figure 2. Homepage of SKIES knowledge management platform 
adopt the appropriate media under 25 subject domains, for example,Language, Aviation, Technology, Science, Nursing, or Education.

In addition, "SKIES Media" has been developed as a plugin which allows teachers to embed media into the HKU SPACE learning management system directly for seamless teaching and learning experiences. With SKIES Media, teachers can organize and share resources in a "Collection"or a "Group". Students can follow a collection of media created by their teachers and receive notifications when new materials are added. Teachers can create a group to share resources with a specific group of students; as well, they can make use of one-click group messaging for announcements.

\section{E-learning Platform}

The e-learning platform, SPACE Online Universal Learning 2.0 (SOUL 2.0), was designed and developed by the Centre for Cyber Learning, and is enhanced continuously,based on e-learning trends and feedback from users. The SOUL 2.0 serves as a one-stop platform allowing learners and teachers to access online learning materials, support collaborative learning and knowledge sharing, and enhance community building and interactions between teachers and students, and students and students.

The features of SOUL 2.0 can be classified into six categories: course content functions, communication and collaboration functions, learning functions, administration and management functions, assignment and assessment functions, and feedback functions. Details of the features of these six categories can be found in Table 1 below.

SOUL 2.0 was customized based on the open source learning management platform MOODLE, one of the most popular learning management systems around the world (Capterra, 2015; MOODLE, 2015).

\section{M-learning SOUL 2.0 APP}

Based on SOUL 2.0, the M-learning SOUL 2.0 App was designed and developed by the Centre for Cyber Learning in order

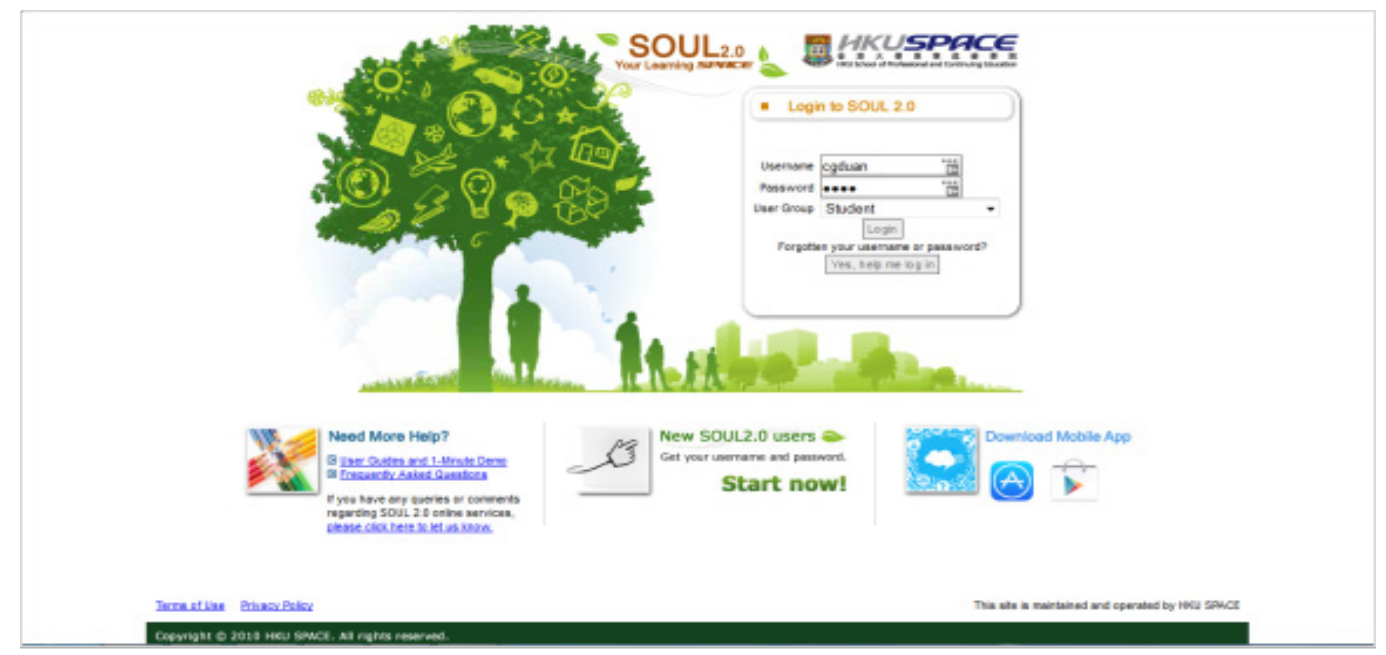

Figure 3. Homepage of SOUL 2 platform 
Table 1. Features of the SOUL 2.0 platform

\begin{tabular}{|l|c|}
\hline \multicolumn{1}{|c|}{ Category } & Specific features \\
\hline Course content functions & $\begin{array}{c}\text { Lesson and course material, audio and video lectures, } \\
\text { streaming courseware, links to supplementary material, } \\
\text { interactive learning courseware, open education } \\
\text { resources, RSS feed, course search engine. }\end{array}$ \\
\hline Communication and collaboration functions & $\begin{array}{r}\text { Discussion forum, virtual classroom, chat room, choices, } \\
\text { database, wiki, blog, message, quickmail. }\end{array}$ \\
\hline Learning functions & Mind map, glossary, tags. \\
\hline Administration and management functions & $\begin{array}{c}\text { Course announcement, calendar, grades, learning resources } \\
\text { management, enrolment management, course layout } \\
\text { management. }\end{array}$ \\
\hline Assignment and assessment functions & $\begin{array}{c}\text { Assignment, quiz, workshop, plagiarism checking (Turnitin), } \\
\text { learning progress tracking, outcome-based assessment } \\
\text { grading. }\end{array}$ \\
\hline Feedback functions & Questionnaires, feedback, surveys, reports. \\
\hline
\end{tabular}

to enhance the flexibility and effectiveness of teaching and learning through the use of mobile devices. The mobile learning application is available in both Google Play Store (Android) and Apple App Store (iOS). Figure 4 shows a screen capture of the SOUL

\subsection{App.}

According to the platform's statistics, from the launch of the APP in September 2014 to March 2015, the total number of downloads was 7,142, with 3,562 from the Google Play
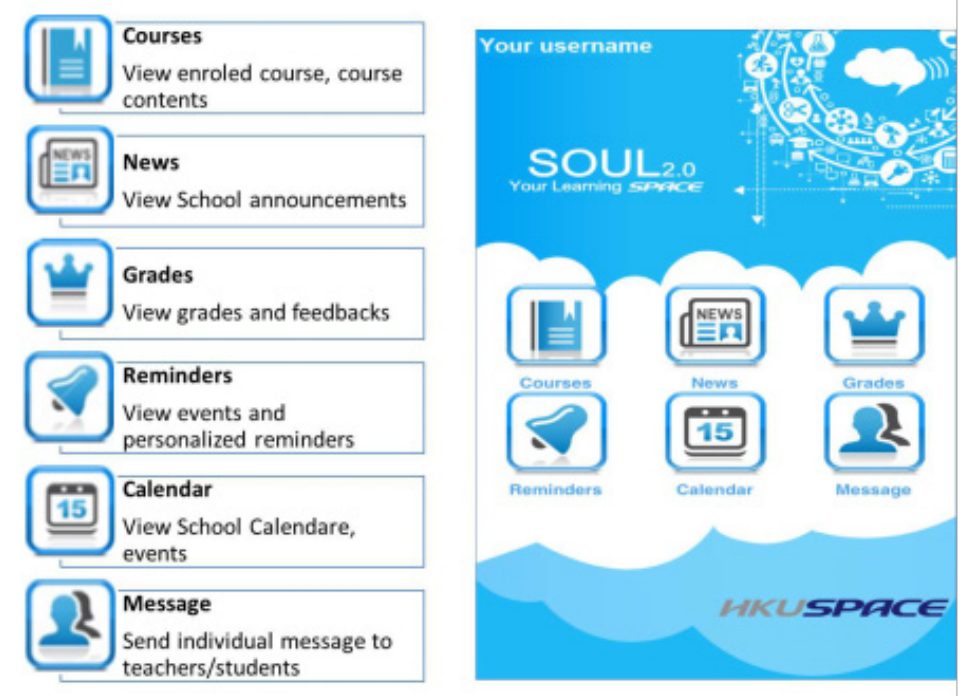

Figure 4. Features of the SOUL 2.0 App 
Store and 3,580 from the Apple App Store. The monthly access to messages, reading materials, forums etc. on the learning platform through the SOUL 2.0 App has been over 40,000, as shown in Table 2.

After the launch of the SOUL 2.0 App, the number of students with access to the e-learning platform has increased from

\section{E-learning Course Design and Development}

E-learning course development is very expensive for self-financed continuing higher education institutions. HKU SPACE is no exception. To better plan the development and continuous enhancement of e-courses based on project areas and financial return, the courses in HKU SPACE were classified into

Table 2. Number of visits to the platform via SOUL 2.0 application

\begin{tabular}{|c|c|}
\hline Month & Count \\
\hline $2014 / 09$ & 22,347 \\
\hline $2014 / 10$ & 42,725 \\
\hline $2014 / 11$ & 43,345 \\
\hline $2014 / 12$ & 40,469 \\
\hline
\end{tabular}

580,311 between September 2013 and January 2014 to 655,924 between September 2014 and January 2015, as shown in Table 3.

According to the statistics above, the numbers of users and the numbers of logins to the desktop version of the learning platform were almost the same in the two specified periods, while the access via the SOUL 2.0App witnessed a rapid growth to almost one-third of the total login access to the desktop version. five levels ranging from face-to-face courses (e0), which have no online components, to entire e-courses (ee) in which all teaching and learning activities are performed online. Table 4 summarizes the characteristics of each e-course level and the respective numbers of courses at HKU SPACE as of April 2015.

Of all the 3,047 courses referred to in Table 5, 1,742 (57.2\%) included at least some e-learning components. In addition, according

Table 3. Access to the platform via SOUL 2.0 app and desktop

\begin{tabular}{|l|c|c|c|c|}
\hline & \multicolumn{2}{|c|}{ Access via SOUL 2.0 app } & \multicolumn{2}{c|}{ Access via desktop version } \\
\hline & No. of users & No. of login access & No. of users & No. of login access \\
\hline Sep. 2013 - Jan. 2014 & -- & -- & 24,356 & 580,311 \\
\hline Sep. 2014 - Jan. 2015 & 5,463 & 154,058 & 23,672 & 501,866 \\
\hline
\end{tabular}


Table 4. The number of e-courses with different levels at HKU SPACE

\begin{tabular}{|c|c|c|c|}
\hline Level & Types of Course & Characteristics & Courses \\
\hline Ee & Entire (Pure) E-courses & $\begin{array}{c}\text { All teaching, learning, interactions, assessment, } \\
\text { evaluation and management online. }\end{array}$ & 2 \\
\hline e3 & Integrated Courses & $\begin{array}{c}\text { e2 \& instructional design and development of } \\
\text { interactive e-learning courseware based on } \\
\text { e-learning pedagogy }\end{array}$ & 81 \\
\hline e2 & Web-enhanced Courses & e1 \& two-way interactions & 236 \\
\hline e1 & Web-facilitated Courses & One-way transmission & 1,423 \\
\hline e0 & Face-to-face courses & No online components & 1,305 \\
\hline Total & \multicolumn{2}{|c}{} & 3,047 \\
\hline
\end{tabular}

to statistics collected in April 2015, the total number of active users on the SOUL 2.0 was 32,237 , including 1,201 teachers/staff and 31,176 students.

In order to help equip the teaching staff with the necessary skills and knowledge to participate in the e-course design and development work and to advance their e-courses with more e-learning components gradually, a series of instructional design templates has been prepared, ranging from the holistic e-learning course design to the application of Open Educational Resources (OERs), as shown in Table 5.

With these e-learning Instructional Design Templates, teachers can upgrade their

Table 5. E-learning Instructional Design Templates prepared by Centre for Cyber Learning

\begin{tabular}{|c|l|}
\hline Templates & Contents \\
\hline Course analysis template & $\begin{array}{l}\text { Needs analysis, learner analysis, content analysis, content structure } \\
\text { analysis, platform function analysis, course delivery mode analysis, } \\
\text { computer skill requirements, online interaction analysis, etc. }\end{array}$ \\
\hline Course design template & $\begin{array}{l}\text { Programme title, course title, teaching and learning hours, teaching } \\
\text { and learning strategies, course content expert, online learning } \\
\text { resources, online learning hours and face-to-face teaching hours, } \\
\text { tutorial hours, etc. }\end{array}$ \\
\hline Unit design template & $\begin{array}{l}\text { Course title, unit title, navigation, learning outcomes, topics, stimulus, } \\
\text { interactive courseware, readings, evaluation, online discussion }\end{array}$ \\
\hline $\begin{array}{c}\text { Template for OERs in } \\
\text { e-learning course development }\end{array}$ & $\begin{array}{l}\text { Unit title, curriculum hours, unit learning outcomes, relationship } \\
\text { between the OERs and the learning outcomes, OERs categorization, } \\
\text { URL, copyright/licenses, notes (e.g. plugins to be installed, etc.) }\end{array}$ \\
\hline Resource construction \\
template & $\begin{array}{l}\text { Text, audio and video clips, SCORM courseware, simulation, game, } \\
\text { interactive exercise, quizzes, case studies, problem solving, etc. }\end{array}$ \\
\hline
\end{tabular}


e-courses from e0, e1, e2, even e3 and ee levels after receiving training and individual support services from the Centre for Cyber Learning professionals.

\section{E-learning Training and Support Services}

The Centre for Cyber Learning offers various e-learning and m-learning seminars and training workshops to internal staff in order to allow them to learn and master new knowledge and skills of e-learning and $\mathrm{m}$-learning. With a better understanding and use, teachers are able to develop and deliver high-quality e-learning and m-learning programmes and courses effectively and efficiently.

In order to familiarize teachers with the SKIES, SOUL 2.0 and SOUL 2.0 App features, a series of hands-on training workshops are conducted on basic functions, interactive learning activities, learningassessment activities and course-management functions. As well, separate hands-on training workshops on the use of advanced functions such as Turnitin, Quiz, Glossary, Questionnaire, communication functions, and resource management functions are provided. In addition, regular student briefing sessions are conducted and customized user training workshops are offered upon request.

Series of training workshops on e-learning pedagogy are arranged to help internal staff understand and adopt e-learning pedagogical approaches. The topics include principles of e-learning, e-learning instructional design, the development of e-learning content, e-learning tutoring and evaluation, knowledge management, the use of virtual classroom, MOOCs and OERs.

A wide range of user support services are also provided to handle user enquiries and resolve problems including email, hotline, an online enquiry system and self-help tools. With an effective user communication mechanism, the School is able to manage enquiries and tackle problems efficiently, which enhances user satisfaction and facilitates the use of e-learning services.

\section{Evaluation of E-learning Courses}

The four-phase evaluation model for e-learning courses is consistent with the HKU SPACE quality assurance system (HKU SPACE, 2011). The e-learning evaluation model includes planning, development, process, and product evaluations, called the PDPP evaluation model. Planning evaluation includes market demand, feasibility, target student groups, course objectives, and finance. Development evaluation includes instructional design, course material design, course website design, flexibility, student-student interaction, teacher/tutor support, technical support, and assessment. Process evaluation includes technical support, website utilization, learning interaction, learning evaluation, learning support, and flexibility. Product evaluation includes student satisfaction, teaching effectiveness, learning effectiveness, and sustainability (Zhang and Cheng, 2012).

\section{Results from Student E-learning Experience Surveys}

The student e-learning experience surveys for e1, e 2 and e 3 courses are administrated by individual programme teams. They are subject-specific and conducted on a voluntary basis, and the entire e-courses use the standard questionnaire with the same items. As the two entire online courses cover all aspects of e-learning and survey data are available, this part of the paper will introduce the survey results for the two pure e-courses entitled Research Methods in Distance Education and E-learning Course Design and Development. 
These two courses were designed and developed specially for programme staff and teachers from open universities and e-learning colleges. They both last for 10 weeks, and the average study hours are about eight per week, that is 80 hours altogether. All the course management, teaching, learning, activities, quizzes, assignments, and discussion sessions take place in e-learning mode. One tutor is allocated to every 20 students. courses, and there were 191 returned, valid questionnaires, representing $56 \%$. The survey results are summarized in Table 6.

Table 6 shows that the majority of students were satisfied with various aspects of e-learning in these two courses, with the rate of strong satisfaction/satisfaction ranging from $71 \%$ to $97 \%$. From overall feedback, the rates of strong satisfaction/satisfaction in learning

Table 6. Survey results of students pure e-learning experiences

\begin{tabular}{|c|c|c|c|c|c|}
\hline & Strongly satisfied & Satisfied & Neutral & Unsatisfied & Strongly unsatisfied \\
\hline Website design & $44 \%$ & $41 \%$ & $10 \%$ & $3 \%$ & $0 \%$ \\
\hline Lectures (Video programme) & $65 \%$ & $30 \%$ & $3 \%$ & $0 \%$ & $0 \%$ \\
\hline Tutors & $69 \%$ & $28 \%$ & $2 \%$ & $0 \%$ & $0 \%$ \\
\hline E-learning course arrangement & $41 \%$ & $49 \%$ & $8 \%$ & $0 \%$ & $0 \%$ \\
\hline Instructional design & $56 \%$ & $37 \%$ & $4 \%$ & $1 \%$ & $0 \%$ \\
\hline E-learning study units & $41 \%$ & $45 \%$ & $11 \%$ & $0 \%$ & $0 \%$ \\
\hline Flexibility of learning & $41 \%$ & $42 \%$ & $14 \%$ & $1 \%$ & $0 \%$ \\
\hline Communication with the tutor & $50 \%$ & $37 \%$ & $10 \%$ & $0 \%$ & $0 \%$ \\
\hline Communication with students & $36 \%$ & $35 \%$ & $24 \%$ & $2 \%$ & $0 \%$ \\
\hline Technical support & $37 \%$ & $41 \%$ & $15 \%$ & $3 \%$ & $1 \%$ \\
\hline Assessment & $34 \%$ & $48 \%$ & $15 \%$ & $0 \%$ & $0 \%$ \\
\hline E-learning environment & $44 \%$ & $41 \%$ & $11 \%$ & $1 \%$ & $1 \%$ \\
\hline Course quality & $54 \%$ & $39 \%$ & $4 \%$ & $0 \%$ & $0 \%$ \\
\hline \multicolumn{6}{|l|}{ Overall Feedback } \\
\hline $\begin{array}{l}\text { All things considered, the course } \\
\text { has been effective in helping me } \\
\text { learn }\end{array}$ & $38 \%$ & $55 \%$ & $6 \%$ & $1 \%$ & $0 \%$ \\
\hline $\begin{array}{l}\text { All things considered, the teacher } \\
\text { has been effective in helping me } \\
\text { learn }\end{array}$ & $51 \%$ & $44 \%$ & $4 \%$ & $1 \%$ & $0 \%$ \\
\hline $\begin{array}{l}\text { A ttending the course has been } \\
\text { worthwhile }\end{array}$ & $70 \%$ & $28 \%$ & $2 \%$ & $0 \%$ & $0 \%$ \\
\hline
\end{tabular}

The online questionnaires for e-learning experience surveys were distributed to all 340 students who participated in these two effectiveness and teaching effectiveness reached $93 \%$ and $95 \%$ respectively, while $98 \%$ of the students felt that their participation 
in these courses had been worthwhile.

The students also made qualitative comments on these two pure online courses in relation to the e-learning platform, e-learning instructional design, e-learning resources, interactions, tutoring, and quality. The following are some of the most typical comments made by the students of these two courses.

I like the iPad style interface of the course homepage very much.

The online learning environment was very user friendly, and the learning support services were well organized.

The course platform was well designed. It was very functional and simple to use.

The opening session was so innovative that a sense of belonging was developed at the very beginning of the course.I had the feeling that I became a student of the HKU SPACE from that day and I was ready to start learning.

This course was well organized. The learning materials were concise and abundant, the multi-media courseware was interactive and innovative, and the learning activities were very engaging and thought provoking.

Overall, this course was well designed. With its clear learning outcomes, and learner-centred learning environment, resources, activities, and evaluation etc., this course had realized the idea of "interactive" online learning. It was a very enjoyable online learning experience.

The arrangement and design of course content was so good, and the tutors' learning support services were also very good.
The tutors and teaching assistants were very professional. They always gave professional answers to students' questions.

The learning support services for this course were very good. Because of this, I adapted to the learning environment quickly.

I think the most exciting design of this course is that it took full consideration of learners' experiences and practical backgrounds to increase the common interest of learning in students. The abundant content and forms of tutoring activities, timely learner support services, especially the timely feedback and reminders from the tutors, made the learners feel the human touch and emotional communication of distance education, and the mutual respect for each other.

Thanks to the abundant teaching resources, strong interactivity and convenient learning environment of this course, I have formed a deeper understanding of online learning.

Overall, I learned a lot from this course. The learning environment and learner support services were so good.

This course was very good at arousing my interest in learning. Online learning makes it possible for me to study anytime and anywhere.

\section{Discussion}

With reference to the findings above, this section will discuss the results and provide some practical implementations of institutional e-learning development in self-financed continuing higher education institutions. 
Establish institutional strategic planning for e-learning sustainable development

E-learning sustainable development requires continuous support from institutions. McGill, Klobas and Renzi (2014) analyzed 64 e-learning initiatives and found that 20 of them (31\%) discontinued because of technology use and institutional support.

Continuing higher education institutions are self-financed without government or university financial subsidization. Costeffectiveness and financial issues are the key factors in the development and sustainable enhancement of e-learning. Therefore, it is essential to have considerate strategic planning and continuous review of e-learning practices based on international trends, local marketing research, subject areas, users' needs analyses, and cost-effectiveness. Therefore, without long-term institutional e-learning development strategies, it would be hard for programme teams and teachers to continue their e-learning initiatives and provide effective e-learning services for their students.

\section{Develop a customized e-learning total solution infrastructure}

The knowledge management system, learning management system, and m-learning app are the three basic components of e-learning infrastructure. These three systems need to be designed and integrated for sustainable development and effective implementation of e-learning from technological perspectives in continuing higher education institutions.

Because of a very high turnover rate of part-time teachers in continuing education institutions, the knowledge management system could be used as a repository of teaching and learning resources. The subsequent teachers could re-use, adapt and adopt these resources in teaching and learning to save costs. With the integration of the systems, teachers could select resources from the knowledge management system and transfer them easily to their own courses for content richness and updates on learning management systems. An m-learning app based on a learning management platform could provide learning environments for teachers and students anywhere and anytime, while their learning and teaching records could be transferred to central database of management systems.

With the advancement of technology, based on knowledge management systems, learning management systems, and m-learning apps, the cloud services could be then used for better performances and to reduce costs. In addition, the plug-ins on tools of learning analytics could be integrated into the learning management systems for big data analysis and the results could be used to improve teaching and learning effectiveness.

\section{Develop and enhance e-learning courses based on needs analysis for cost effectiveness}

The e-learning infrastructures are used for e-learning course development and delivery. E-learning course design and development is high-cost for self-financed continuing higher education institutions. Therefore, the standards of priority for developing different levels of e-courses have to be considered. The levels of e-learning modes could be developed from web-facilitated and web-enhanced learning, and then advanced to blended and pure online learning. The priority of e-course development for different levels should be considered based on subject areas, course content, student characteristics, student numbers, financial return, content update, current and future marketing in order to maximize the costeffectiveness. 


\section{Provide user training and individual support services for e-learning and m-learning}

Although teachers are encouraged to use e-learning modes to enhance teaching and learning effectiveness through institutional policy and different committees, e-learning is not compulsory for them. As the majority of teachers are on a part-time basis, they are not able to provide effective e-learning support to students without professional training and individual support services. Therefore, the training workshops and individual support services have to be provided when e-learning and m-learning systems and pedagogy are used by internal professionals.

\section{Conclusion}

This paper has described and analyzed an institutional development framework and practices in e-learning in continuing higher education institutions, using HKU SPACE as a case. Based on the results of the research, the authors have identified the importance of strategic planning, including policy and organizational structure for the sustainable development of e-learning, a customized total e-learning solution in infrastructure for resource sharing and technology support, e-course development and enhancement with different levels based on needs analyses for cost effectiveness, and training and individual support services for the effective use of e-learning in continuing higher education institutions.

\section{References}

Akyol, Z., \& Garrison, D. R. (2014). The development of a community of inquiry over time in an online course: Understanding the progression and integration of social, cognitive and teaching presence. Journal of Asynchronous Learning Networks, 12(34), 3-22.

Capterra (2015). The top 20 most popular LMS software [EB/OL]. http://www. capterra.com/learning-managementsystemsoftware/\#infographic, 2015/201507-23

Czerniewicz, L., \& Brown, C. (2009). A study of the relationship between institutional policy, organisational culture and e-learning use in four South African universities. Computers \& Education, 53(1), 121-131.

Giesbers, B., Rienties, B., Tempelaar, D., \& Gijselaers, W. (2013). Investigating the relations between motivation, tool use, participation, and performance in an e-learning course using webvideoconferencing.Computers in Human Behavior, 29(1), 285-292.

Graham, Woodfield \& Harrison (2013). A framework for institutional adoption and implementation of blended learning in higher education. Internet and Higher Education 18 (2013) 4-14.

Guan, C., Ding, D., \& Ho, K. W. (2015). E-Learning in higher education for adult learners in Singapore. International Journal of Information and Education Technology, 5(5), 348-353.

Gunn, C. (2010). Sustainability factors for e-learning initiatives. Research in Learning Technology, 18(2), 89-103.

Hall, J. P. (2013). Is my instructor there for me? A study of reflective practice and student perceptions of online teaching 
presence. ProQuest LLC.

HKU SPACE (2011). Evaluation on e-learning programme/course development based on student learning experiences in five pilot programmes/courses. (For internal use, unpublished).

HKU SPACE (2011). Quality assurance manual, HKU SPACE.

HKU SPACE (2012). Survey on student experiences and needs of e-learning support services. (For internal use, unpublished).

HKU SPACE (2013a). Survey on HKU SPACE staff development and training needs. (For internal use, unpublished).

HKU SPACE (2013b). Blended learning policy. (For internal use, unpublished).

HKU SPACE (2015). 2015 Spring Prospectus, Hong Kong: HKU SPACE.

McGill, Klobas \& Renzi. (2014). Critical success factors for the continuation of e-learning initiatives. Internet and Higher Education, 22 (2014),24 -36.

MOODLE (2015). MOODLE Statistics. https://MOODLE.net/stats/?lang=en, 2015/2015-07-23

O'Dowd, R. (2013). Telecollaborative networks in university higher education: overcoming barriers to integration. The Internet and Higher Education, 18, 47-53. Pawlyn, J. (2012). The use of e-learning in continuing professional development: Jill Pawlyn shares findings from a study of the factors that influence learning disability nurses to choose e-learning for workrelated education. Learning Disability Practice, 15(1), 33-37.

Scanlon, E., McAndrew, P., \& O'Shea, T. (2015). Designing for educational technology to enhance the experience of learners in distance education: How open educational resources, learning design and MOOCs are influencing learning. Journal of Interactive Media in Education, 2015(1). 6, 1-9.
Singh, K. and Bajaj, J. S.(2015).Using technology to deliver cost-effective Continuing Professional Development (CPD). Ann Natl Acad Med Sci (India), 51(1\&2): 45-53.

Taylor, J. A., \& Newton, D. (2013). Beyond blended learning: A case study of institutional change at an Australian regional university. The Internet and Higher Education, 18, 54-60.

Wanner, T., \& Palmer, E. (2015). Personalising learning: Exploring student and teacher perceptions about flexible learning and assessment in a flipped university course. Computers \& Education, 88, 354-369.

Zhang, Weiyuan (2013). Entering the 3rd generation of E-learning: Characteristics and strategies.Journal of Educational Technology Development and Exchange, Vol. 6, Issue 1, 1-12.

Zhang, Weiyuan \& Cheng, Y. L. (2012). Quality assurance in e-learning: PDPP evaluation model and its application, The International Review of Research in Open and Distance Learning, Vol. 12, No. 1, 6682.

\section{Contact the Author}

Dr. Weiyuan Zhang

Professor of School of Educational Technology

Beijing Normal University

Beijing, China

Email: zhangweiyuan@bnu.edu.cn

\section{Chenggui Duan}

E-learning Manager, Chu Hai College of Higher Education

Hong Kong

Email: cgduan@chuhai.edu.hk 